\title{
CAMINITOS AL MARGEN DEL MUNDO EVALUADOR: pasajes metodológicos de una crítica de la razón evaluadora
}

\author{
Facundo Giuliano \\ Instituto de Investigaciones Sociales de América Latina (Consejo Nacional de \\ Investigaciones Científicas y Técnicas) - IICSAL-CONICET, Argentina
}

\begin{abstract}
Resumen
En este artículo se conjugan los pasajes metodológicos de una investigación filosófica, literaria y educativa que ensaya una crítica de la razón evaluadora. Siguiendo esta clave, por su propia singularidad, se necesitó hallar senderos o caminitos al margen del mundo evaluador que impone recetas de investigación, metodologías cristalizadas o prescripciones epistemológicas que disfrutan de un amplio consenso en el campo de las Ciencias Humanas en general y de la educación en particular. Frente a ese panorama, en estas páginas se entreteje una doble trama que combina la desnudez de una insurgencia metodológica (donde el problema aparece insinuado o ubicado como telón de fondo) y la observación sensible de reflexiones epistémicas (en cuyo seno se dan cita los motivos afectivos, colectivos y vitales del acto de investigar). De este modo, pueden encontrarse las desobediencias, la indisciplinariedad (en contraposición a la interdisciplinariedad), la descolonización y la deconstrucción como puntos de partida que hacen a un tejido escritural capaz de combinar elementos liberadores y subversivos en su arte de investigar. Así se ponen en juego nociones y percepciones que suponen algún tipo de enfrentamiento (agón) como dimensión política insoslayable de una travesía epistémica trans-formativa.
\end{abstract}

Palabras claves: Desobediencia epistémica; Investigación indisciplinada; Filosofía de la educació; Metodología de la investigación.

\begin{abstract}
The In this article, the methodological passages of a philosophical, literary and educational investigation that essay a critique of evaluative reason are combined. Following this key, due to its own uniqueness, it was necessary to find paths outside the evaluating world that imposes research recipes, crystallized methodologies or epistemological prescriptions that enjoy a wide consensus in the field of Human Sciences in general and education in particular. Against this background, in these pages a double plot is woven that combines the nakedness of a methodological insurgency (where the problem appears insinuated or located as a backdrop) and the sensitive observation of epistemic reflections (where the affective, collective and vital of the act of investigate are thought). In this way, disobediences, indisciplinarity (as opposed to interdisciplinarity), decolonization and deconstruction can be found as starting points that make a scriptural fabric capable of combining liberating and subversive elements in its art of research. Thus, notions and perceptions are brought into play that suppose some kind of confrontation (agon) as an unavoidable political dimension of a trans-formative epistemic journey.
\end{abstract}

Keywords: Epistemic disobedience; Undisciplined research; Philosophy of education; Research methodology. 


\section{Informalidades de partida: desobediencia, descolonización, deconstrucción}

En sus "Breves notas sobre ciência", el pensador angoleño Gonçalo Tavares (2018) sugiere que no se llega a un resultado, sino a una metodología. Y, si recordamos la asociación benjaminiana del método al desvío, quizá puedan leerse estos pasajes en-tramados como "aquello que se hace tras haber tropezado" (TAVARES, 2018, p. 262).

En el andar de esta búsqueda se intenta entender una problemática a partir de elaboraciones que podrían mencionarse como 'crítico-hermenéuticas' o, más específicamente, descolonizadoras y deconstructivas en torno a autores/as, nociones, percepciones, sensaciones y un insoslayable anudamiento filosófico-educativo que pone un estado de cosas en cuestión. Se recurre a fuentes por realizar diferentes análisis críticofilosóficos, poniéndose en juego -a partir de las posiciones epistémicas de base- la interpretación mediante una hermeneusis ${ }^{1}$ descolonial y la deconstrucción de argumentos que sustentan ciertos discursos históricamente hegemónicos.

Así se plantea un compromiso con una bibliografía de base, alentando la discusión de los ejes polémicos que surjan de los respectivos cuestionamientos que constituyen la problematización ofrecida, procurando el logro de aproximaciones que habiliten otras formas de pensar, habitar y conversar lo filosófico-educativo. En este contexto, resulta clave la apuesta por develar nuevos sentidos metodológicos en torno a la idea de lo indisciplinario que Rancière (2012) opone a lo inter-disciplinario (es decir, al mero recorte en temas sobre los cuales cada disciplina está llamada a aportar su contribución $)^{2}$, lo cual implica explorar cooperativa y singularmente las zonas de indeterminación que existen en el contenido de cada disciplina. Esto no podría realizarse sin poner en práctica cierta desobediencia epistémica que implica un desenganche de los mandatos disciplinarios -según han sido configurados por la modernidad/colonialidad y la vigente matriz colonial de poder-, esto es, avanzar en el "activo abandono de las formas de conocer que nos sujetan, y modelan nuestras subjetividades en las fantasías de las ficciones modernas" (MIGNOLO, 2014, p. 7).

Como ya se ha advertido, entre otras nociones de relevancia para este planteo, se retoma la noción de deconstrucción en tanto experiencia que consiste en deshacer "un sistema de pensamiento que se nos revela como único y/o hegemónico y/o dominante" (SKLIAR, 2006, p. 19), y resulta de importancia para estudios críticos o problemáticas como la razón evaluadora (GIULIANO, 2019a, 2019b). Del análisis de textos a la reflexión filosófica, lo escrito desnuda un tiempo heurístico de intensa búsqueda bibliográfica, estudio de fuentes ${ }^{3}$ y discursos ${ }^{4}$ actuales -así como un relevamiento y revisión crítica de las elaboraciones respecto de ellos- a partir de los aportes realizados por especialistas, instituciones y referentes del campo pedagógico. Lo cual también denota una temporalidad hermenéutico-crítica en la que se procura acceder con cierta hondura a los textos para analizar sus categorías centrales, reconstruir argumentos y plantear eventuales re-conceptualizaciones, a modo de promover un acercamiento de reflexión que saque filo en torno al problema-núcleo de la investigación. (Como si leer fuera el ejercicio espiritual -a veces silencioso- y escribir el 
ejercicio físico-deportivo donde el temblor viaja de los ojos a los pies, pasando por las manos sedientas de pulsaciones).

Esta forma de estudio pone los sentidos en juego permitiendo, de este modo, abordar con cierta minucia las retóricas actuales de la razón evaluadora y su relación con la alteridad y la subjetividad en el campo de la educación. Son arte y parte de este planteo la conversación y la discusión periódica de sus vueltas y revueltas, ya sea en el marco de reuniones que suelen apellidarse "científicas" (pero no solamente ellas), en publicaciones o encuentros y desencuentros con pensadores/as afines al marco epistémico propuesto. Esto último va en línea con lo que hemos llamado, tal vez con poca sutileza, una ética de la conversación (GIULIANO, 2017a) y con la centralidad que la conversación adquiere en el planteo de una investigación indisciplinada (HABER, 2011). Pues se trata de un estar tendido hacia algún sentido, aunque no inmediatamente accesible, que habita en los límites o los bordes del sentido mismo como desviación singular de un conmover(se) mínimo. Una huella tajeante, un corte en la indiferencia insensata, que muestra cómo los sentidos se inquietan entre sí cuando la voz de la escritura (o la escritura de la voz) resuena como música de los registros sensibles: cada sentido toca a los otros y se toca al sentir.

\section{Afección, convite, investigación: gestualidades de encuentro}

Una pasión moviliza, afecta, toca y es tocada por un roce exterior que inspira la música del pensamiento. En movimiento, en afección, en fricción podría decirse que comienza a escribirse (a veces sin letras, sin páginas, sin pluma) una investigación, cuando esta surge del deseo y no de la imposición, la conveniencia, la impostación. Tanto en el deseo como en el movimiento epistémico de su búsqueda, no se está del todo en soledad. Siempre hay otro, siempre hay otra, que enciende una fogata invitadora a la reunión, a la revelación, a la rebelión. Con fuego se batalla, se forja el arma, se quema la maleza, o puede incluso cortarse otro fuego, darle otra forma al hierro y cocinar algún sabroso plato. Este podría ser el arte de investigar: una pulsión que presentifica el curiosear de infancia, una acción que va abriendo senderos entre los espinales, un trazo más o menos explícito que va grabando indicios en la piel de la memoria.

Investigar, entonces, como cita y convite al pensamiento, a la travesía, a la traducción, a la escritura, a la conversación. Una invitación que aloja un deseo y descubre un tiempo intenso de caminar un acontecimiento junto a otros. Pues, aunque exista alguna íntima motivación, siempre involucra a más de uno en alguna diferencia no teleológica, pero sí existencial. La complicidad tramada no permite irse del mismo modo como se ha llegado, las inquietudes devenidas de las texturas del mundo y las voces docentes desnudan problemas que pueden ir de lo ético a lo político o de lo epistémico a lo pedagógico y viceversa.

La búsqueda de diferencias respecto de esa pedagogía moderna/colonial que se encuentra plagada de certezas teórico-prácticas repetidas hasta el hartazgo sin más, abre las puertas internas de la reflexión y hace del andar de la conversación un caminar por senderos pedagógicos junto a maestras y maestros del pensamiento contemporáneo. Tal vez porque 
sea necesario barajar (o repensar) y dar de nuevo, ya que "quien se sabe que sabe" de educación tiene demasiado claro cómo son las cosas, o cómo deberían ser, en base al clásico cúmulo de recetas, ya sean tecnocráticas, más o menos críticas, más especializadas o, incluso, tematizadas. De este modo se presenta una figura grotesca bastante clásica a evitar: el pedabobo (un reproductor indiferente de pedanterías epistemológicas y boberías impostadas, que embrutece a cada trazo de su certeza).

Frente a ello, preferimos el gesto de lectura como escucha de las palabras y los silencios en sus motivaciones de infancia (GIULIANO, 2020e), anti-pragmáticas, inútiles desde un principio. Porque un testimonio guardan los signos públicos y políticos que adquieren fuerza de herencia epistémica: un guiño antes de una situación, un gestito de idea luego de una exaltación; deseo desinteresado, una otredad deshaciendo lo uno; proximidades y distancias en una travesía común difícil de olvidar, aunque imposible de memorizar; ni presupuesto ni resultado, devenir que sólo se entiende con; desconocimiento esencial como condición del saber no sabido; relación de lejanías próximas y conversación de al menos dos silencios; el misterio de los gestos y la enigmática presencia de una escucha sin condición; afección de lo incontable e incomparable, pero de lo que acompaña aun en el desvío; soledad dislocada donde las voces inaccesibles de otros se escuchan en la propia.

\section{Indisciplinas y desobediencias del lenguaje}

Si la pedagogía es “ese conjunto de discursos más o menos especializados que sirve para nombrar lo que hay, lo que pasa o lo que nos pasa en una serie de ámbitos vitales o existenciales determinados, los que tienen que ver con la educación" (LARROSA, 2010, p. 108), notaremos enseguida que mayormente esos discursos se muestran excesivamente preocupados y ocupados en el conocimiento objetivante, la investigación "empírica", el diagnóstico y/o la gestión de lo real. De este modo, priman las miradas distantes, más o menos etnográficas, los vínculos utilitarios con "informantes" o abridores de puertas institucionales, la reificación (y verificación) de las desigualdades de partida, las descripciones "densas" a dos o tres columnas (que indicarían el lugar de lo visible, lo subjetivo y lo categorizable), etc.

Como una de las problematizaciones claves de nuestra investigación tiene que ver con lo establecido como "válido", será un recurso echar mano de ciertos discursos que suelen tener la potencia de suspender el juicio (GIULIANO, 2020b), es decir, que producen efectos que pueden escaparse a la racionalidad evaluadora por el hecho de sorprender, conmover o "golpear" cualquier procedimiento de validación o aprobación (GIULIANO, 2018a) de lo establecido como "real" o "correcto". Aquí se juega la indisciplina propia de cierta literatura, de cierto cine, de cierto arte o de cierta filosofía (GIULIANO, 2019c; 2020a; 2020d; 2020e). Por ello, en nuestro planteo, que podría estar en sintonía con lo "nometodológico"5 (HABER, 2011), hay nociones de partida en juego, pero no un esquema metodológico pre-establecido que requiere siempre de procedimientos de objetivación, cosificación, tematización, representación y moralización. Antes bien, implica estar abierto para dejarse afectar por lo que acontece en el camino de la investigación, por las preguntas que se nos plantean durante 
y las inquietudes o curiosidades que se constituyen en desvíos ético-políticos que enriquecen los planteos de partida, por un movimiento de alteridad -que reclama acompañamiento en la relación que se establece con lo que se presenta- y no de identidad -que siempre juega a algún papel representacional o policial-. Se trata de la atención en contraposición al juicio y a la mera buena intención, atención en cómo se junta el lenguaje y el mundo, lo (in)inteligible y lo sensible, el sentido y la experiencia, cuestión constitutiva del relato y del ensayo que se tornan potencias en lo que tienen de resto in-evaluable (GIULIANO, 2020c) por el cual apuesta la escritura de esta investigación intentando evitar "técnicas de escrituras, letanías auto-justificativas, banalidades [o vanidades] metodológicas" (LARROSA, 2010, p. 110).

Por ende, resulta clave también la noción de desobediencias del lenguaje constituida por el ritmo de la conversación, la poética, los juegos, el humor, los enigmas y las incógnitas irresolubles, las aporías y las ambigüedades éticas, la alteridad de la adivinanza, la gestualidad contra la infamia, las traducciones inconclusas, los relatos imposibles, los olvidos y actos fallidos, la impaciencia con lo dado, lo inexplicable, lo in-apacible, lo que nos pone en "esa brecha -sonora y silenciosa- que abre la posibilidad de un sentido" (SKLIAR, 2015, p. 16). El ejercicio de estas desobediencias entra en sintonía no solo con la búsqueda planteada, sino con la propia praxis de resistencia y, por tanto, de re-existencia que abren alternativas frente a lo impostado por el lenguaje de la razón evaluadora. Además, esto nos permite, al menos en parte, no solo liberar la aiesthesis (el sentir) que generalmente suele quedar presa del lenguaje formal, serio y normalizado que suele utilizarse en la escritura científica, sino también ponerla en juego.

\section{Urgencia conversacional: compartir y vivir el pensamiento}

Así, se habita una urgencia singular. La premura radical de detener el tiempo, de suspender certezas, de conversar a-penas, de pensar a corazón abierto, de un gesto abrazador, de la amorosidad con cualquiera, de pensar juntos lo impensado, de quedarnos perplejos ante la invitación de alguna palabra que altere un orden de cosas. Tal vez un sentido ético y antipragmático de lo urgente, nos enseña que la invitación es pregunta y la pregunta puede ser conversación (GIULIANO \& ZANETTI, 2020; GIULIANO et al., 2020). Es decir, una emergencia del pensamiento que interpela no ya como esa prisa cronológica que unos pocos definen como prioritaria a favor de sí mismos, sino como precipitación imposible e impasible que irrumpe en medio de la normalidad por dar lugar a lo eternamente postergado tal vez en cualquier lugar conocido entre (nos)otros: la igualdad. De esto se trata quizá un investigar con los pies en el barro del presente: escrituras y lecturas se encuentran, en el interior de una conversación infinita, al escucharse sin más o por mirarse sin menos, la diferencia, la igualdad no homogeneizante.

Lo dicho recibe su matiz peculiar, su tono, el gesto que lo acompaña, la refracción del pensamiento donde intentan reflejarse nuestras palabras inquietas con toda la belleza posible. Esa atmósfera impregnada de sensibilidades hace de una conversación una de las maravillas epistémicas del mundo: cada cual es quien está-siendo y lo que está diciendo, sin término 
absoluto. Y acontece así el momento en que hallamos esa enseñanza milenaria de las palabras: bolsos semánticos en los que se comparte la vida, una manera de estar en el mundo y la fuerza de un pueblo. Aquí resuena la voz enseñante del filósofo qom Timoteo Francia (y TOLA, 2011), para quien siempre fueron importantes los conceptos de compartir, saber recibir y ofrecer gratuitamente no solo sabidurías, sino también la savia de las palabras. Porque compartir, saber-recibir y ofrecer las palabras, es también compartir, saber-recibir y ofrecer sentimientos, pensamientos y deseos. Como cierta filosofía qom del lenguaje muestra, "las palabras pueden tener una repercusión sobre la realidad material ya que ellas "corren, vuelan, viajan' llevando los sentimientos, pensamientos y deseos de quienes las emitieron" (TOLA, 2012, p. 172). Así se singularizan, devienen independientes, se separan de quien las emitió y cumplen con lo expresado. Pero antes hay una lengua que las pronuncia, un cuerpo que las sostiene y que las siente tanto como las piensa. O como mejor dice Timoteo Francia en una frase bonita: "Uno no tiene que olvidar el pasado y el presente. En nuestro cuerpo queda pegado, en el corazón, una marca, un mensaje se graba y jamás se borra, queda para siempre" (citado en TOLA, 2012, p. 170).

Así tal vez podría vivirse en carne propia el pensamiento antes que la teoría, alterando ciertos puntos de vista (a veces demasiado empíricos, otrora demasiado racionales) y permitiendo experiencias de investigación que admitan a sus pies embarrarse en la ficción, esa que se construye quizá después que se la ha vivido, en un juego colectivo de huellas e invención que enseña su lengua como invitación o desafío de gesto abierto hacia otredades convocadas al fogón de la conversación, de la curiosidad, de la hospitalidad inscrita en un acontecimiento que ya estaba en marcha...

\section{Fagocitación contestataria y ejercicio descolonial del agón (y la parresía).}

La posición epistémica en juego permite visualizar a la teoría (construida al mismo tiempo que es ejercitada) como un elemento de lucha que posibilita ocuparnos de las contradicciones, las incertidumbres, las estrategias, los cuidados, de las críticas, resistencias y transgresiones que puedan plantearse, siguiendo aquí el trazo de Linda Smith (2016), investigar contestatariamente hacia esa misma lógica que hizo de la investigación el encuentro entre Occidente y el Otro con su respectiva cosificación. Cuestión que necesariamente nos lleva a involucrar la noción de fagocitación, desde el singular enfoque que Kusch (2007a, p. 180) le da, es decir, una forma de absorción de la pulcritud de Occidente por el hedor de América como modo de "reintegración de lo humano en estas tierras", en "un terreno de imponderables, en aquel margen de inferioridad de todo lo nuestro, aun de elementos acumulados, respecto a lo europeo (...) Es cuando tomamos conciencia de que algo nos impide ser totalmente occidentales, aunque nos lo propongamos". Por ende, una práctica de fagocitación contestaría sería la que nos permite advertir problemas como los que encontramos en grandes referencias del pensamiento que quizá sin advertirlo del todo han reproducido lógicas que se sitúan entre el racismo epistémico y la razón evaluadora, al 
tiempo que podemos vislumbrar alternativas liberadoras desde nuestro estar (como se explora en GIULIANO, 2018b; 2020h; 2020i). ${ }^{6}$

Este planteo indisciplinado nos involucra también en cierto ejercicio descolonial del agón -más comúnmente entendida como contienda, desafío, disputa- que nos permite profundizar determinados debates y discusiones con aquellos discursos o retóricas que fundamentan o fortalecen la racionalidad evaluadora (como se ensaya, por ejemplo, en Giuliano, 2019e). Decimos que se trata de un ejercicio descolonial del agón porque, en la contienda que se plantee, la discusión o debate no buscará la prevalencia de una posición sobre la otra o la "victoria" de una de las partes sobre la otra -lo cual sería hacer un uso clásico de dicha noción y quedar presos de lo mismo-, sino luchar por la re-existencia de lo que la lógica de la colonialidad no permite existir y abrir paso a alternativas por ello inéditas. Teniendo en cuenta lo planteado por Mignolo (2001), no se busca una superación sino otra opción, otro lugar de enunciación, un paradigma otro. Para nuestro problema, concretamente, no se trata de aniquilar la razón evaluadora (que sin dudas seguirá existiendo y tomando nuevas formas cada vez), sino de dejar en evidencia sus tejidos y manipulaciones que hace invivibles los espacios y tiempos en los que manda, para habilitar otras espacialidades y temporalidades que resistan y re-existan a la lógica cruel que la constituye. No hay lugar aquí, entonces, para esa aspiración que suele llamarse "neutralidad", que no es más que otro nombre para la muerte.

En este contexto, ese ejercicio combate también "la visión común anti-política que se niega a reconocer la dimensión antagónica constitutiva de 'lo político"' (MOUFFE, 2007, p. 10, énfasis nuestro). Por ende, esta dimensión involucra no solo la distribución de fuerzas y diferencias epistémicas, sino más precisamente "El diferencial colonial que recicla, potencia y reproduce, antagonismos de clase, raza y género" (HABER, 2011, p. 19, énfasis nuestro), ubicándonos al filo de la frontera que define nuestro proceso de subjetivación al interior de la propia investigación y que se torna necesario problematizar. Podría decirse que es la parte muscular de la investigación que, al contraerse, busca la acción -a veces en forma de ataque o de defensa- y que, al relajarse, porque nada del medio genera inquietud, puede hasta dormirse. En este sentido, Tavares (2018, p. 199) alerta que, como enseña el rápido estudio de la fisiología corporal, el relajamiento sucesivo, la ausencia de tensiones y contradicciones provoca "una lenta pero inequívoca decadencia los tejidos" y "Sin la presencia visible de adversarios, los músculos preparan meticulosamente su propia derrota".

La observación realizada constituye una necesaria dimensión conflictual que, aunque sea soslayada por investigaciones que responden a la corrección política o la lógica del consenso, atraviesa las dimensiones principales que Kohan y Masschelein (2015) reconocen en la investigación educativa (referirse a algo educacional; tornar algo público; provocar alguna transformación en el investigador) y no la mencionan o explicitan quizá por lo mismo que se la suele evitar u omitir. Pues se sabe también que hay sobradas investigaciones referidas a algo educacional, que tornan algo público y quizá transforman algún aspecto de quien investiga (haciéndole más eficaz en la recolección de datos y su posterior descripción o categorización, o más sensible a determinados marcos, o más sistemático en su pensamiento, etc.) sin que esto implique ningún riesgo, ninguna lucha puntual, ningún cuestionamiento al 
statu quo o al orden de cosas en el mundo. De hecho, investigaciones liberales como las promovidas por House y Howe (2001) hacen de quien investiga un evaluador cuyo proceder busca brindar a la evaluación una función social más fuerte y una mayor autoridad en la toma "pública" de decisiones, por lo que se ufanan de emplear "criterios públicos" (por más que no aclaran qué entienden por lo público, que suele reducirse a la publicidad o a un público selecto) para evaluar y, desde ahí, gesticular sus imposturas. ${ }^{7}$

La dimensión conflictiva mencionada, que podría caracterizarse por necesitar de cierto coraje, consideramos que está dada por cierta práctica parresiasta, es decir, por el hecho de involucrarnos con una verdad que tal vez no quiere ser escuchada por buena parte de la sociedad y, por ello, nos compromete en una posición de inevitable fragilidad. ${ }^{8}$ Se trata, en suma, de llevar a cabo una investigación indisciplinada como forma de "seguir el negativo de las huellas que persisten aun no estando, (...) escuchar lo no dicho de las palabras" (HABER, 2011, p. 29), de intentar a toda costa resistir y agrietar la hegemonía de la metodología disciplinada moderna/colonial en cuya base se encuentran los protocolos de acción que pretenden trazar el camino que se ha de seguir para alcanzar algún tipo de conocimiento aceptable.

\section{Interrogación vital: no hay preguntas tontas, si se sienten y se piensan}

Las preguntas, otro nombre para eso que llamamos problemas, no surgen de una factoría ni de fábricas especializadas, no son como cualquier otra cosa. Pueden tomarse elementos de aquí y allá para su dibujo, pero si no son impuestas, se tratan de fragmentos de vida. De ahí surge todo un arte de la interrogación vital.

Recuerdo mi maestra de primer grado del primario decir que tengamos cuidado con hacer preguntas tontas. ¿Por qué habrían de existir preguntas "tontas" en la infancia? ¿Acaso no es patrimonio común de la humanidad la famosa "edad de los por qué"? ¿No es desde allí que comienza un movimiento, una curiosidad y una inquietud fundamental? Claro que hay preguntas imposibles, difíciles, incómodas, que alteran o pasan de largo, que se esconden, que buscan una no-respuesta o más de una voz, las hay rebeldes o sin causa, las hay inquisidoras y no-éticas, las hay de muchas clases y formas. Pero la pregunta denostada es inconcebible, la pregunta descalificada, sea de infancia o alteridad, lo es porque no se le dio lugar o, lo que puede ser igual y peor, no se la sintió/pensó en lo que ella guardaba de invitación.

Sin pregunta no hay curiosidad, no hay posibilidad de narración como intento de decir lo que se piensa o lo que se insinúa. Como esa escena típica donde los por qué de la infancia que interpela, es respondida teleológicamente por la adultez certera que dice "para tal cosa o para tal otra...": como si viviéramos en una época donde la pregunta existencial del por qué se respondiera incesantemente con la voz pragmática o el tono instrumental del para qué. Podría recordarse a la pensadora que en su juventud se rebeló ante este panorama de utilidades y cambió las coordenadas cuando le preguntaron: ¿Para qué vas estudiar filosofía? Y ella respondió: Porque no puedo dejar de hacerlo. Aquí se traza un contorno 
ejercitable que podría subvertir las preguntas pragmáticas de nuestro tiempo: quizá cada para qué podría responderse con al menos un por qué.

Si todo está en orden, quieto o inmóvil, una pregunta podría sonar desafiante. Como para esas personas que habría un libreto de preguntas ya escritas o formuladas de las que no deberíamos salir: no preguntar fuera del marco, no preguntar fuera de lo ya dicho, no preguntar generalidades, ser específico, técnico, especialista, fidedigno, exégeta, sacerdote. Nada más insoportable, consideramos, que un orden sustentado por la instalación del miedo a la pregunta (tanto en quienes quisieran hacerlas como en quienes tendrían que darle hospedaje). Quizá un miedo a que se pregunte algo que nos movilice del lugar donde estamos o que nos sacuda la aparente calma, un miedo de que no se pregunte para "mostrar lo que ya se sabía, lo que ya se poseía, lo que ya se suponía” (SKLIAR, 2011, p. 306), en resumen, un miedo a la pregunta que no exige respuestas o, sobre todo, a preguntas inadaptables a respuestas que no excedan el tiempo mínimo estipulado, respuestas de un único tiempo, de una única respiración, de un rostro sin cuerpo.

Cada palabra vertida en pregunta puede ser un temblor compartido. Esa ha sido una de las mejores enseñanzas que nos ha brindado "Bartleby" sobre cómo responder a las preguntas inquisidoras de la mismidad, en forma honesta, pero con la ambigüedad propia de lo real: preferiría no hacerlo. Las preguntas de aquí y las respuestas de allá pueden ser extranjeras por venir de otro lugar, pueden irrumpir como un desconocido, pueden irritar por su aparente ingenuidad o su torpe pronunciación. Pero esa es la desnudez de más de uno, es la desnudez del otro junto a otras, es de la desnudez de las preguntas por la sinrazón y el desconocimiento del mundo. La perplejidad hecha pregunta, o formulada como respuesta interrogante, no se impone ni se interfiere: a-penas se comparte.

\section{Analéctica y desprendimiento.}

Nuestra postura, por tanto, es más analéctica que dialéctica precisamente porque no buscamos una síntesis conciliatoria o consensual más o menos pacífica sino la afirmación radical de una exterioridad y no solo la negación de la negación del sistema que afirma la totalidad. Siguiendo a Dussel (2011), es un combate contra la totalidad, pero no como actualidad de lo que está en potencia en el sistema, sino como afirmación de la exterioridad que implica realizar un imposible para el sistema, realizar un imprevisible para la totalidad, lo que surge desde la libertad en rebelión.

Por lo expuesto, estamos lejos de realizar un planteo metodológico "puro" o previamente legitimado por el consenso científico-pedagógico actual. Si, tal como enseña Zambrano (2011, pp. 69-74), un método "es un camino a recorrer una y otra vez", algo inmediato donde el comienzo es a la par un final, aunque lo que se proponga sea un tiempo sucesivo a recorrer, coincidimos con ella en que tal impostura termina por convertirse en una "forma mentis" que hermetiza lo vital y remite todo a los resultados, a cierta obsesión por "cifrar la condición humana en modos de dominación sobre la naturaleza", sobre la sociedad en diferentes niveles, sobre el tiempo y sobre la interioridad (o subjetividad) que surge como 
antagonista destinada a ser vencida por algún procedimiento de objetivación, o cierta explicitación más o menos ideal, o por la mera necesidad (muchas veces burocrática) de "empiria". Frente a esto, estamos con ese "especial desprendimiento", captado por Zambrano (2011, p. 81) -y también por Mignolo-, que remite a algún signo a seguir o a una enseñanza de algo sin forma explícita, "una insinuación, una alusión que sugiere algo que hacer" y también que no hacer...

Por eso, desde nuestra perspectiva, no consideramos que investigar sea evaluar ni compartimos la postura de que cuando se investiga se evalúa en el afán de admitir una supuesta ruptura con una idea de objetividad a la que el mismo acto de evaluar le superpone otra idea de objetividad menos pura y que incluiría las implicancias del sujeto investigador (lo cual no hace más que re-adaptar la objetividad o hacerla más inclusiva). En esta línea se inscriben investigaciones apellidadas evaluativas que se realizan con objetivos determinados para fines específicos en el marco de un contrato donde el investigador es patrocinado para recabar información sobre algún tipo de rendimiento asociado generalmente a las inversiones de los patrocinadores en un programa.

\section{Invitación vital: el lugar filosófico como lugar de la pregunta que pide alojo}

Preguntar, entonces, como invitar. Una pregunta siempre puede ser una buena ocasión para encontrarse y el resto hacerle compañía. Preguntar e invitar suponen un gesto mínimo que interpela de manera amorosa o ambigua, que cita a pensar(nos) con, a preguntar(se), a responder mínimamente con la hospitalidad de la escucha. Un alojar la pregunta hospedándola sin que importen los supuestos, los saberes, las certezas, las legalidades, más que para ponerse en cuestión. Cuando alguien pregunta y otro responde en dos palabras hondas "me mataste...", algo indica que la pregunta posee alguna dimensión mortífera de la que habría que guardar especial cuidado. Pues no se pregunta para matar, excepto que nos volvamos inquisidores o, peor aún, evaluadores. Nada más alejado del preguntar como invitación, como gesto, como potencia de encuentro y compartir. Sí podríamos decir que la pregunta posee una dimensión finita, de finitud, no de fin teleológico (aunque muchas la tengan y se haga uso y abuso), porque tal vez preguntamos para no morir en soledad ni dejar morir al otro en sus propias palabras o sus propias certezas, o para morir juntos en medio de un lenguaje común que no se ha escrito todavía. Preguntamos porque quisiéramos explorar lo que no redunda, lo inexplorado, lo infiel, lo no dicho, lo no pensado, lo indecible o impensable. Aunque algo nos separa y nos aúna, sean tiempos o años, sean geografías o travesías, la inquietud interrumpe la ausencia allí donde nunca habíamos estado. Y comenzamos meramente a estar y habitar lugares comunes del pensamiento: allí donde nunca (nos) habíamos preguntado o donde se ha dejado de preguntar, allí donde no hay mucho lugar para la respuesta pronta-entera-satisfecha-segura-acabada. Así se transmite una enseñanza que no tiene las claves de su propio saber: da las pistas por desenclavar las palabras prohibidas o silenciadas, da lugar a lo indecible y lo indecidible que habita los márgenes. 
Ir y volverse pregunta, ampliar los límites del campo de lo pensable, atravesar las regiones iluminadas por una oscuridad que inquieta cualquier familiaridad y reaviva lo que se creía mantenido en el olvido o en el secreto. Se torna necesaria una atención sensible al cuerpo que da carne a las palabras, aprender a escuchar lo inaudible de una experiencia que asiste a un pensamiento sintiente en el momento mismo de su enunciación: quienes conversan despliegan una trama rugosa que da lugar al asombro y expone sus desgarraduras. La voz de la palabra irrumpe en un espacio incognoscible y nos detiene azorados en el instante de los silencios y las melodías del pensamiento. La emoción de una indefinible inquietud por lo que acontece en la voz, habla del lugar desconocido que jamás domesticaremos, aunque lo habitemos durante el encuentro. Los ojos pueden detenerse ante las palabras, pero no pueden reducir o fragmentar su misterio para aclararlo o pasar de lo desconocido a lo conocido, porque eso sería aprehender y matar una incógnita. Y sí que se mata, más seguido de lo que imaginamos, mediante gestualidades, como cuando se dice "ya conozco" o "ya sé, ya sé", cuando se hace hábito del pensamiento dominante o de la razón evaluadora como amo indiscutible que devora el asombro (aunque este la disloque cuando la pasea por la enigmática noche de los claros del día).

Una pregunta inmemorial o a-etaria, una pregunta previa por ese lugar impropio, que rechaza el pensamiento en su función de comprensión inmediata, pero que es preciso abrir o habilitar en cualquier parte, trata de abrir zonas que subsistan al pragmatismo y puedan dar lugar a que pueda surgir lo inesperado. Tal vez sea un lugar filosófico que implica "el punto de arranque e incluso el camino que orienta la indagación, donde uno no ejerce totalmente el juego reflexivo, sino donde se infiltra la alteridad a través del juego, haciendo vislumbrar un sentido en general que escapa a lo pensable", donde "se diluye lo que soy, el ser al que me aferro, y donde no logro determinar qué es lo que está, pero donde todo lo que está pesa con todo su misterio" (KUSCH, 2007b, pp. 384-390).

\section{Sobre el archivo (evaluador) la arqueología y la genealogía}

Lo anterior no quita que también podamos sumergirnos en búsqueda de lo que Foucault (2008) llamó regularidades específicas, que nos relacionan de manera interpelante con las cosas dichas y los sujetos que las han dicho, a la vez que conforman un sistema de discursividad con las posibilidades e imposibilidades enunciativas que este dispone. Aquí es donde entra en juego la noción foucaultiana de archivo y que fagocitaremos para hablar de la constitución de un archivo evaluador -que posee su propia ley de lo que puede ser dicho, su propio sistema que rige la aparición de sus enunciados-. Pues el archivo

es también lo que hace que todas esas cosas dichas no se amontonen indefinidamente en una multitud amorfa, ni se inscriban tampoco en una linealidad sin ruptura, y no desaparezcan al azar sólo de accidentes externos; sino que se agrupen en figuras distintas, se compongan las unas con las otras según relaciones múltiples, se mantengan o se esfumen según regularidades específicas 
(...) En su totalidad, el archivo no es descriptible, y es incontorneable en su actualidad. Se da por fragmentos, regiones y niveles... (FOUCAULT, 2008, pp. 170-171).

Por tal motivo, aparece de manera singular en nuestro andar el término arqueología no como incitación a la búsqueda ${ }^{9}$ de algún comienzo particular, alguna excavación o sondeo geológico, sino como cuestión general que "interroga lo ya dicho en el plano de su existencia: de la función enunciativa que se ejerce en él, de la formación discursiva a que pertenece, del sistema general de archivo de que depende. La arqueología describe los discursos como prácticas especificadas en el elemento del archivo" (FOUCAULT, 2010, p. 173). Profundizando esta noción, Agamben (2009, pp. 124-141) llama arqueología a "aquella práctica que, en toda indagación histórica, trata no con el origen sino con la emergencia del fenómeno y debe, por eso, enfrentarse de nuevo con las fuentes y con la tradición. No puede medirse con la tradición sin deconstruir los paradigmas, las técnicas y las prácticas a través de las cuales regula las formas de la transmisión" y dicha emergencia se ubica en un umbral de indecibilidad con el que la "regresión arqueológica" lidia no para restablecer un estado precedente sino para "descomponerlo, desplazarlo y, en último análisis, cercarlo", remontándose así a sus modalidades y a momentos de escisión.

Tampoco se puede eludir algo de la meticulosidad de la indagación genealógica, la cual trata de evocar un fantasma al tiempo que se lo (re)constituye, se lo (re)elabora y se lo detalla progresivamente hasta erosionarlo. Resulta de importancia para nuestra investigación porque, como sostiene Deleuze (2016, p. 9), la genealogía "se opone tanto al carácter absoluto de los valores como a su carácter relativo o utilitario" e involucra un elemento diferencial que no es mera "crítica del valor de los valores sino el elemento positivo de una creación" - lo cual aporta a la concepción de la (actividad) crítica como una acción que se opone a la mera reacción-. Desde esta perspectiva, la crítica no es una re-acción del resentimiento, sino la expresión activa de un modo de existencia: el ataque creativo y no la venganza, la agresividad crítica de una manera y no el rencor de la aversión, esto es, el manejo del elemento diferencial "como crítico y creador" o, para citar una materialidad nietzscheana, "como un martillo" (DELEUZE, 2016, p. 10). ${ }^{10}$

Además, resulta especialmente pertinente para esta investigación la noción de genealogía porque, tal como Foucault (1996, p. 18) la planteara, posibilita el "redescubrimiento meticuloso de las luchas" y la "memoria bruta de los enfrentamientos" a la par que acopla el saber erudito y el saber popular local en aras de eliminar la tiranía de los discursos jerarquizantes con todos sus privilegios. De este modo, podemos explorar de otros modos la constitución de la racionalidad evaluadora mediante una actividad genealógica que no es un proyecto empirista ni positivista, sino que se trata de poner en juego "saberes locales, discontinuos, descalificados, no legitimados", contra la instancia evaluadora misma que pretende "filtrarlos, jerarquizarlos, ordenarlos en nombre de un conocimiento verdadero" y de los privilegios "de una ciencia que sería poseída por alguien” (FOUCAULT, 1996, p. 19). Siguiendo el planteo foucaultiano, las genealogías son precisamente anti-ciencias en el sentido de que promueven una insurrección o una lucha de los saberes justamente contra los 
efectos de poder de un discurso determinado generalmente como científico (como para aquí podría ser el discurso propio de la razón evaluadora). La genealogía adquiere así el carácter de una indisciplina contra los proyectos de inscripción de los saberes en la jerarquía de los poderes propio de las ciencias (de la educación, para lo que aquí concierne) y una especie de tentativa de liberar de la sujeción a los saberes para hacerlos capaces de lucha contra la coerción de un discurso unitario, formal, científico. Así, entran a escena los saberes locales, "menores", contra la jerarquización del conocimiento evaluador y sus efectos intrínsecos de poder: ahí radica la necesidad de cierto desorden y de lo fragmentario en las genealogías. ${ }^{11}$

\section{Investigar vital: cuestión de suelo y no de juicio}

¿Y qué investigar puede privarse de la torpeza, la fragilidad, el tartamudeo vital que hacen al encanto del azar que no se deja capturar, recortar, mutilar, probabilizar? Aquí tal vez radique una fuente (y una fuerza) de vida epistémica que persevera en el estar de un encuentro entre exterioridades inconmensurables e in-evaluables (GIULIANO, 2020c). Porque reconocer no es encontrar y cerca del juzgar está, es que el oficio infantil de investigar se marchita cuando se hace garantía de adulta formalidad o corte suprema escritural. Es por esto que tal vez se halle más pensamiento en el barrendero que en el juez, pues mientras uno acostumbra a lidiar con la intimidad del suelo y sus habitantes, el otro se aleja de las verdades de la tierra y se (a)sienta sobre una altura ficticia desde la cual mira a los demás. El barrendero se apoya en el palo de la historia cuando se cansa, el juez se reclina sobre sus culpables de inocencia mientras dictamina su próxima sentencia. El tribunal de la Razón Pura alecciona y mezquina enseñanza, más allá que haya gente deseando ser juzgada con tal de ser "reconocida" bajo la insignia de la culpa. El suelo de las calles, quizá como una interminable conversación barrial, multiplica los lados, desnutre los dualismos de sus veredas, descompone la máquina binaria que preside la distribución de papeles y que hace pasar por preguntas pre-fabricadas a todas las respuestas ofertables en función del cálculo de las significaciones dominantes. Quizá por este motivo el suelo del pensamiento en la investigación suele ser ninguneado, al tiempo que se consolida un etéreo proceder que rinde pleitesía al patrón que teje su imperialismo o colonialidad y hace que todo aquello que no pase por él pueda ser desoído, desestimado, desechado. Es lo mismo que nos hace pensar que estamos hablando en nombre propio al mismo tiempo que otro pretendidamente universal habla desde su rincón europeo a través nuestro y nosotros hablamos por quienes no podrán hacerlo.

Tocamos así la politicidad del investigar cuando este se manifiesta en su pulsión por liberar el sentir y el pensar en su localidad, en su marginalidad, en su exterioridad. Bordes que no quieren el encierro del reconocimiento, sino la apertura a los encuentros con los lapsus linguae de la historia, las fallas geográficas del pensamiento y las catástrofes de una naturaleza implacable. En el fondo late una apuesta de amistad con el error, la equivocación, el traspié o resbalón, puesto que anuncian la necesidad de desprendimiento del enemigo colonizador interno que acecha: la razón evaluadora que examina, juzga y condena. De allí 
se avista un movimiento guiado por el deseo de saber y no por el resultado de investigar que suele someter el pensamiento a una imagen seriada. Deseo de saber que es multiplicidad desbordante o ingenio creativo de una enunciación colectiva que es conversación y no un coloquio, ni un debate prefabricado por especialistas, ni tan siquiera una interdisciplinariedad ordenada de acuerdo a un proyecto común.

Lo que importa del caminito que se hace al andar son sus líneas de continuidad que no se detienen a recapitular, ni aspiran al regreso ni al progreso, pero sí a pensar, a sentir, cada vez más su experiencia de alteridad, de paseo, de travesía, con más ética, más política, más vida. Una manera interesante de leer: los contrasentidos son brújulas, los pensamientos suenan, colorean, dibujan las intensidades que afectan, trastocan, pasan o no pasan. Así tal vez se escriba una filosofía popular del investigar: las cuestiones nunca pasan allí donde se cree que van a pasar, ni por los caminos que se espera.

\section{Laberinto escritural/conversacional y erres...}

Tampoco puede perderse de vista que también se trata de un laberinto escritural y conversacional del que quizá nunca se salga o donde solo los otros pueden brindar las pistas para tener alguna noción de por dónde ir... Y, lo que va escribiéndose, en tanto la investigación va trazando su propio camino en el laberinto con idas y vueltas, sinuosidades y senderos ocultos, atajos y pozos que enlentecen el paso, enseña un andar que difícilmente pueda reconstruirse totalmente a partir de la positividad de las huellas. Quizá porque, como advierte Agamben (2009, p. 7), quien está familiarizado con la práctica de la investigación en ciencias humanas, la reflexión sobre el camino no precede, sino que viene después de la andanza y "se trata de pensamientos de algún modo últimos o penúltimos". O quizá porque no coleccionamos los intervalos, las caminatas entre un lugar y otro, aquello que no puede enseñarse sin alguna textura o sabor, se pierde(n). Y, si de la herejía de la memoria aparece una invención, la mayor dificultad reside no en los errores, que convocan una guitarra al compás del erre con erre, sino en la exactitud que destruye la vitalidad de esa cuna de sentidos pedagógicos que son los actos fallidos (GIULIANO, 2016).

Por eso también las textualidades surgidas de esta posición ético-epistémica no son sometidas al escrutinio de un "corrector de estilo", pues asumimos el estilo de quien falla en sus limitados recursos, de quien puede alimentarse de algunas letras y de quien puede osar en repetir alguna conexión, alguna palabra, algún vicio de carácter orto-tipo-gráfico. De igual forma que no hay aventura sin un proceder incorregible, sin el paso a otro lado y sin la necesidad de una traducción instantánea (o futura):

Escribir como traducción de leer. Una traducción no solo incorrecta, equivocada; más que eso: desastrosa. Escribo intentando traducir entre dos lenguas idénticas lo que he leído, pero me equivoco, de ahí la creatividad; invención como fallo evidente, no en la repetición sino en el intento de pasar algo a otro lado. (TAVARES, 2018, p. 256) 
Se trata también de no ocultar la fragilidad de la palabra escrita y dar lugar a sus grietas, como diría Tununa:

la errata es un irreversible, es ella la que señala la vulnerabilidad de la palabra escrita, es por sus grietas donde se desliza el sentido buscando donde anidar de nuevo, como un órgano que busca compensar sus funciones en otros o en algún fragmento de sí mismo (MERCADO, 2003, p. 45).

O también de que las erratas permitan esas grandes cosechas que anhelaba Macedonio:

Hay que reintentar la Errata, porque esta decadencia de la literatura universal debe provenir de que se llevan los escritos al tipógrafo ya pasados a máquina, o sea revisados. (...) Quién sabe si no tendríamos una resurrección del gran arte literario, de las grandes cosechas metafóricas y adjetivales (FERNANDÉZ, 2004, p. 328).

Y luego de la andanza tal vez entendamos que acudir al lugar es una manera de saber, no solo si quien grita socorro lo quiere dar o recibir, también si preferimos la rebelión a vivir padeciendo.

\section{Notas}

1. Comúnmente asociada al arte (o la ciencia) de narrar, traducir, o interpretar, sobre todo textos para establecer algún significado o sentido de las palabras mediante las cuales se ha expresado un pensamiento.

2. Por lo tanto, la inter-disiciplinariedad no sería otra cosa que "un paso más en la saturación del espacio de aprendizaje a través de la distribución oficial de los saberes y de sus modos de adquisición" (RANCIĖRE apud GIULIANO, 2017a, p. 216).

3. Se toman como referencia aquellos desarrollos, mapeados como estado del asunto, que sustentan alguna forma de la razón evaluadora.

4. Se busca también investigar posibles experiencias o posicionamientos filosófico-educativos que den que pensar la evaluación de otro(s) modo(s) o evidencien rebates, prácticas de resistencia o contra-hegemónicas.

5. Haber (2011) refiere a lo nometdológico como un marco que desplaza la investigación desde la objetualización hacia la situacionalidad, adoptando la forma de una arqueología indisciplinada, una conversación ampliada en la inmediatez de espacio-tiempos discontinuados en la colonialidad. Supone seguir aquellas posibilidades que el camino olvida, que el protocolo obstruye, que el método reprime. Sigue los negativos de las huellas y las relaciones entre estos, lo que significa que sea acerca de la violencia disciplinaria: se pregunta por aquello que el método ha obligado a soslayar, por aquello que la disciplina desoye, por lo que nos haría sospechosos de subversión.

6. Esto último puede que sea lo que Walter Kohan (2020) no llega a ver o confunde de nuestro planteo, reducido para él a señalar como coloniales a determinados autores y pensamientos, cuando en realidad el problema se sitúa a nivel de las operaciones filosóficas a las que habitualmente se acostumbra: por ejemplo, inscribir algún pensador no-europeo en alguna tradición europea para darle cierto prestigio o una importancia "mayor" que no necesita. Es llamativo que operaciones inversas no suelen asomar en este tipo de tejes y manejes que reinstalan una lógica re-occidentalizante o directamente eurocéntrica. Si la cuestión 
"más compleja" es algo que se dirime en lecturas colonizadoras o descolonizadoras de diversas tradiciones, sería interesante ver qué descolonización se juega en subsumir un pensamiento no-europeo a uno europeo o en buscar alguna sucursal de Sócrates en Caracas, Pernambuco o el lugar no-europeo que se prefiera. Si son "los usos y sentidos otorgados a un pensamiento los que tienen un valor colonizador o descolonizador" (KOHAN, 2020, p. 82), ¿qué sucede con el racismo epistémico que vive en forma latente o, a veces, manifiesta en algunos pensamientos? ¿Será que un uso y sentido con "valor descolonizador" es suficiente para neutralizarlo y reproducirlo sin mayor inconveniente? Difícilmente el hacer descolonizador pueda reducirse al "uso" de un pensamiento (aunque pueda encontrarle sentidos subyacentes), pues no se trata de un valor (menos todavía en las variantes de uso o de cambio): es una forma de re-existencia ético-política.

7. El objetivo predefinido de ese tipo de investigaciones levanta las banderas de la inclusión, el diálogo y la deliberación, diciendo que da voz a los marginados y excluidos, pero no sin inducirles los términos o “criterios razonados" que para ellos garantizarían la deliberación e interacción dialógica con "públicos significativos" (ceñidos a la lógica de la audiencia) e interesados por la evaluación que al satisfacer esos requisitos consolidaría una investigación "democrática, imparcial y objetiva". En el marco de planteos epistémicos como el de House y Howe (2001, p. 26), la evaluación sería así la institución cognitiva que, en las sociedades "democráticas y capitalistas avanzadas", sirve "para discernir las afirmaciones verdaderas de las falsas y determinar el valor de los productos, programas, políticas y actuaciones" así como somete a deliberación y debate los puntos de vista de la ciudadanía "por lo que se refiere a su mérito". Por tal motivo, investigador y evaluador coinciden en un mismo sujeto investigador que busca hacerse "acreedor" de la confianza del público y que a veces requiere ser un hábil "negociador" por la "responsabilidad fiduciaria" que tienen con respecto a quienes participan de su montaje. Un análisis detallado de la noción de responsabilidad vinculada a la evaluación y el neoliberalismo puede encontrarse en Giuliano (2020f).

8. Tal como enseña Foucault (2011) sobre la práctica de la parrhesía, se trata de una modalidad del decir veraz que involucra una actitud, una manera de hacer o procedimientos que implican la manifestación de un lazo fundamental entre la verdad dicha y el pensamiento de quien la ha expresado tanto como el cuestionamiento del lazo entre quien dice la verdad y aquel a quien está dirigida -lo cual abre, instaura o afronta, el riesgo de ofender al otro y suscitar una serie de conductas que pueden llegar a expresar diferentes tipos de violencia-. Supone un decir que desnuda alguna verdad sin reservas o cláusulas de estilo, ni ornamentos retóricos que pueda cifrarla o enmascararla, por eso requiere de cierto coraje con respecto a todo y contra todo.

9. Al percibir cierta insistencia de la palabra 'búsqueda' o 'buscar' en estos pasajes, otra vez Tavares (2018, p. 259) pareciera dar en el clavo cuando dice que "la «expectativa de encontrar» mueve a quien colecciona y a quien investiga. Dos actividades que miran aparentemente hacia sitios opuestos: hacia el día de mañana, hacia lo que todavía no existe (investigación), y hacia el día de ayer, lo que ya existe (colección)", pero una se imbricaría en la otra porque ambas suponen "poner al lado" dos materialidades, y remata: "si el investigador les da más importancia a los parecidos que a las diferencias, entrará en el campo de la pedagogía".

10. Deleuze (2016, p. 110) sostiene que únicamente una ciencia activa es capaz de interpretar las actividades y las relaciones reales entre las fuerzas. Esta se presenta, desde dicho planteo, bajo tres aspectos: I) una sintomatología, "puesto que interpreta los fenómenos, tratándolos como síntomas, cuyo sentido habrá que buscar en las fuerzas que los producen"; II) una tipología, "puesto que interpreta a las propias fuerzas desde el punto de vista de su cualidad"; III) una genealogía, puesto que se preocupa por "el origen de las fuerzas desde el punto de vista (...) que halla su ascendiente en la voluntad de poder, y en la cualidad de esta voluntad". Mencionada ya la importancia que adquiere la indagación genealógica para nuestra investigación, los aspectos de una "sintomatología" y una "tipología" en relación crítica a la razón evaluadora aporta importantes interpretaciones de sus actividades y relaciones de fuerza en lo que de ellas hace síntoma y adquiere determinada cualidad (como puede notarse en GIULIANO, 2017b).

11. Para Foucault (1996, p. 20), "la arqueología sería el método propio de los análisis de las discursividades locales y la genealogía sería la táctica que, a partir de las discursividades locales así descritas, hace jugar los saberes, liberados de la sujeción, que surgen de ellas". Para nuestra aventura necesitamos, como ya se ha 
anticipado, de una arqueología indisciplinada y los mejores juegos que la genealogía puede ofrecer. Algo que puede observarse, por ejemplo, cuando se traza una pregunta que va desde la matriz colonial de poder a los dispositivos pedagógicos contemporáneos (GIULIANO, 2019d), cuando se investiga la colonialidad pedagógica en las pedagogías apellidadas 'críticas' (GIULIANO, 2019f), cuando se indagan las relaciones entre la razón evaluadora y la razón punitiva (GIULIANO, 2019g), o cuando se remueven pistas de herencias indisciplinadas y legados de rebelión (GIULIANO, 2020g).

\section{Referências}

AGAMBEN, Giorgio. Signatura rerum. Buenos Aires: Adriana Hidalgo, 2009.

DELEUZE, Gilles. Nietzsche y la filosofía. Barcelona: Anagrama, 2016 [1962].

DUSSEL, Enrique. Filosofía de la liberación. México: Fondo de Cultura Económica, 2011.

FERNÁNDEZ, Macedonio. Textos selectos. Buenos Aires: Corregidor, 2004.

FOUCAULT, Michel. Genealogía del racismo. La Plata: Altamira, 1996.

La arqueología del saber. Buenos Aires: Siglo Veintiuno, 2008.

El coraje de la verdad: el gobierno de sí y los otros II. Curso en el Collège de France (1983-1984). Buenos Aires: Fondo de Cultura Económica, 2011.

FRANCIA, Timoteo. y TOLA, Florencia. Reflexiones dislocadas: pensamientos políticos y filosóficos qom. Buenos Aires: Asociación Civil Rumbo Sur/Facultad de Filosofía y Letras-UBA, 2011.

GIULIANO, Facundo. La educación, entre la mismidad y la alteridad: Un breve relato, dos reflexiones cuidadosas y tres gestos mínimos para repensar nuestras relaciones pedagógicas. Voces y silencios. Revista Latinoamericana de Educación, v. 7, n. 2, p. 4-18, 2016. DOI: <https://doi.org/10.18175/vys7.2.2016.02>

Rebeliones éticas, palabras comunes. Conversaciones (filosóficas, políticas, educativas) con Judith Butler, Raúl Fornet-Betancourt, Walter Mignolo, Jacques Rancière, Slavoj Žižek. Buenos Aires: Miño y Dávila, 2017a.

. Del sujeto y la repetición en la educación al reconocimiento ético como acto educativo, Araucaria. Revista Iberoamericana de Filosofía, Política y Humanidades, v. 19, n. 38, 265-284, 2017 b. Disponible en URL: 〈https://revistascientificas.us.es/index.php/araucaria/article/view/3432>

. Aprobación/desaprobación: dos caras de la razón evaluadora. Un debate filosófico y algunas claves de resistencia. Voces de la educación, v. 3, n. 6, p. 85-92, 2018a. URL: <https://dialnet.unirioja.es/servlet/articulo?codigo $=6521970>$

Situar a Paulo Freire: entre el racismo epistémico y la razón evaluadora. Una lectura crítica desde la Filosofía de la Educación, Pensando-Revista de Filosofía, v. 9, n. 17, 191-225, 2018 b. <https://revistas.ufpi.br/index.php/pensando/article/view/6424 >

- ¿Tienes razón evaluación? Notas para la profundización de una noción filosófica de la educación. Revista Electrónica Educare, v. 23 n. 1, p. 405-426, 2019a. DOI: <https://doi.org/10.15359/ree.23-1.20>

Desnudar la razón evaluadora. Elementos para un combate filosóficoeducativo. Pensamiento. Revista de Investigación e Información Filosófica, v. 75 n. 287, p. 1451-1474, 2019b. DOI: <https://doi.org/10.14422/pen.v75.i287.y2019.004 >

- ¿Realidad de la ficción evaluadora o ficción de la realidad evaluadora? Apuntes literarios y cinematográficos para una crítica de la razón evaluadora. Discusiones filosóficas, v. 20 n. 35 , p. 149-165, $2019 \mathrm{c}$.

URL: $\langle\underline{\text { https://revistasojs.ucaldas.edu.co/index.php/discusionesfilosoficas/article/view/316/251 }>~}$ 
. Entonces, ¿qué es un dispositivo? De la matriz colonial de poder a los dispositivos (pedagógicos) contemporáneos. Voces de la Educación, v. 4 n. 8, p. 28-68, 2019d. URL: < $\underline{\text { https://dialnet.unirioja.es/servlet/articulo?codigo=7017237> }}$

. Escuela y colonialidad. Variantes e invariantes (estéticas) de la clasificación social,

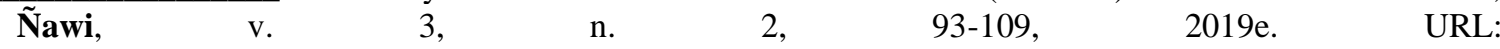
<http://www.revistas.espol.edu.ec/index.php/nawi/article/view/554/428>

La razón evaluadora en las pedagogías críticas. Reflexiones sobre la colonialidad pedagógica desde América Latina (1954-2019). Revista Estado y Políticas Públicas, n. 13, 145-166, 2019 f. URL: 〈http://hdl.handle.net/10469/15851 >

Razón evaluadora/razón punitiva: relaciones y complicidades (o dos caras de la colonialidad pedagógica). Revista Humanidades, v. 10 n. 1, 122-141, 2019g. DOI: <https://doi.org/10.15517/h.v10i1.39678>

. La razón evaluadora entre temporalidades discontinuas y repartición de lo sensible. Del culto evaluacionista a una educación indisciplinada. Cuadernos de Filosofía Latinoamericana, v. $41 \mathrm{n}$. 122, p. 151-192, 2020a. 〈https://doi.org/10.15332/25005375/4643>

Razón evaluadora y escenarios del juicio educativo. Pensamiento Actual, v. 20 n. 34, p. 74-90, 2020b. DOI: 〈https://doi.org/10.15517/pa.v20i34.41836>

Psicoanálisis y educación: acerca de lo imposible versus la razón evaluadora. ECOSEstudos Contemporâneos da Subjetividade, v. 10 n. 1, p. 123-144, 2020c. URL: <http://www.periodicoshumanas.uff.br/ecos/article/view/3028 >

Fragmentos (literarios, pedagógicos, filosóficos) de una crítica de la razón

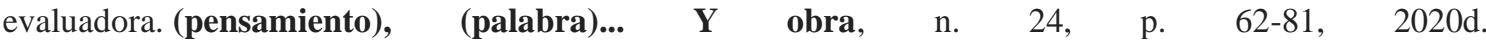
<https://doi.org/10.17227/ppo.num24 >

. Infancia y razón evaluadora: contrariedades y resistencias pedagógicas (entre filosofía y literatura). Enunciación, v. 25, n. 24, en prensa, 2020e. DOI: 〈https://doi.org/10.14483/22486798.16294>

. La razón evaluadora y sus maneras: aparatos de empequeñecimiento y mercantilismo pedagógico, Estudios, n. 40, p. 1-32, 2020f. DOI: 〈https://doi.org/10.15517/re.v0i40.42023>

. Herencias indisciplinadas, legados de rebelión: derivaciones ético-pedagógicas para una crítica de la razón evaluadora (a 100 años de la Reforma Universitaria del 18 y 50 años del Mayo Francés),

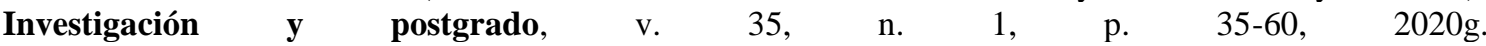
<http://revistas.upel.digital/index.php/revinpost/article/view/8499>

. La razón evaluadora en Paul Ricoeur. Trazos por un desarme de la máquina que ajusticia, Revista Dialectus, v. 9, n. 19, p. 25-37, 2020h. DOI: 〈https://doi.org/10.30611/2020n19id61570>

. Destinos que no tienen pruebas: Pedagogías conjeturales, gestos inevaluables, errancias incorregibles, arte de la (actitud) crítica, Revista Rupturas, v. 11, n. 1, p. 1-24, 2020 i. <https://revistas.uned.ac.cr/index.php/rupturas/article/view/3390>

GIULIANO, Facundo \& ZANETTI, L. La unidad secreta en la enseñanza de Noé Jitrik: una conversación entre subversión, infancia y experiencia, Caderno de Letras, n. 38, p. 373-391, 2020. Disponível em :< https://periodicos.ufpel.edu.br/ojs2/index.php/cadernodeletras/article/view/19254>

GIULIANO, Valentina et al. En vuelo con una rara avis: conversaciones con Tununa Mercado, Estudios de Filosofía Práctica e Historia de las ideas, n. 22, p. 1-29, 2020. Disponível em: <http://mail.qellqasqa.com.ar/ojs/index.php/estudios/article/view/385>

HABER, Alejandro. Nometodología Payanesa: Notas de metodología indisciplinada (con comentarios de Henry Tantalean, Francisco Gil García y Dante Angelo). Revista chilena de antropología, n. 23, p. 9-49, 2011.

HOUSE, Ernest R. y HOWE, Kenneth R. Valores en evaluación e investigación social. Madrid: Morata, 2001. KOHAN, Walter. Paulo Freire más que nunca: una biografía filosófica. Buenos Aires: CLACSO, 2020. 
KOHAN, Walter y MASSCHELEIN, Jan. Prefacio/Correspondencia ¿El pedagogo y/o el filósofo? Un ejercicio: pensar juntos. In: KOHAN, Walter. Viajar para vivir: ensayar. La vida como escuela de viaje. Buenos Aires: Miño y Dávila, 2015, pp. 15-50.

KUSCH, Rodolfo. Obras completas. v. 2. Rosario: Fundación A. Ross, 2007a.

Obras completas. v. 3. Rosario: Fundación A. Ross, 2007 b.

LARROSA, Jorge. Herido de realidad y en busca de realidad. Notas sobre los lenguajes de la experiencia. In: CONTRERAS, J. y PÉREZ DE LARA, N. (Comps.) Investigar la experiencia educativa. Madrid: Morata, 2010, pp. 87-116.

MERCADO, Tununa. Narrar después. Rosario: Beatriz Viterbo, 2003.

MIGNOLO, Walter. Introducción. In: MIGNOLO, Walter. (Comp.) Capitalismo y geopolítica del conocimiento. El eurocentrismo y la filosofía de la liberación en el debate intelectual contemporáneo. Buenos Aires: Del Signo, 2001, pp. 9-53.

Desobediencia epistémica: retórica de la modernidad, lógica de la colonialidad y gramática de la descolonialidad. Buenos Aires: Del Signo, 2014.

MOUFFE, Chantal. En torno a lo político. Buenos Aires: Fondo de Cultura Económica, 2007.

RANCIERE, Jacques. Pensar entre disciplinas. In: FRIGERIO, G. y DIKER, G. (Comps.) Educar: (sobre)impresiones estéticas (pp. 283-291). Buenos Aires: Del estante, 2012.

SKLIAR, Carlos. Pensar al otro sin condiciones (desde la herencia, la hospitalidad y la educación). In: Skliar, C. y Frigerio, G. (comps.) Huellas de Derrida: ensayos pedagógicos no solicitados. Buenos Aires: Del Estante, 2006, pp. 11-31.

Lo dicho, lo escrito, lo ignorado. Ensayos mínimos entre educación, filosofía y literatura. Buenos Aires: Miño y Dávila, 2011.

2015.

Desobedecer el lenguaje. (Alteridad, lectura, escritura). Buenos Aires: Miño y Dávila,

SMITH, Linda Tuhiwai. A descolonizar las metodologías. Investigación y pueblos indígenas. Santiago: LOM, 2016.

TAVARES, Gonçalo M. Enciclopedia. Zaragoza: Xordica, 2018.

TOLA, Florencia. Yo no estoy solo en mi cuerpo: cuerpos-personas múltiples entre los tobas del Chaco argentino. Buenos Aires: Biblos, 2012.

ZAMBRANO, María. Notas de un método. Madrid: Tecnos, 2011.

\section{Correspondência}

Facundo Giuliano: Doctor por la Facultad de Filosofía y Letras de la Universidad de Buenos Aires. Por la misma casa de estudios, es Licenciado en Ciencias de la Educación con estudios focalizados en Filosofía, Psicoanálisis y Literatura. Director del proyecto de investigación FiloCyT "Educación, filosofía y psicoanálisis: la potencia de un anudamiento indisciplinario frente al capitalismo contemporáneo" con sede en el Instituto de Investigaciones en Ciencias de la Educación (UBA). Pertenece al Consejo Nacional de Investigaciones Científicas y Técnicas (CONICET, Argentina). Ha sido profesor/investigador visitante de la Universidad Complutense de Madrid y de la Universidad de Barcelona, donde también ha dictado clases y conferencias. Ha dictado seminarios de grado y posgrado, y publicado en revistas de circulación internacional sobre cuestiones que vinculan problemáticas propias de la educación, la filosofía, la literatura, el psicoanálisis y la política. Actualmente se desempeña como 
profesor de posgrado en universidades nacionales de Argentina. Autor de "Rebeliones éticas, palabras comunes. Conversaciones (filosóficas, políticas, educativas) con Judith Butler, Raúl Fornet-Betancourt, Walter Mignolo, Jacques Rancière, Slavoj Žižek” (Miño y Dávila, 2017) y de "¿Podemos pensar los noeuropeos? Ética decolonial y geopolíticas del conocer" (del Signo, 2018).

E-mail: giulianofacundo@gmail.com

Texto publicado em Currículo sem Fronteiras com autorização dos autores. 